\title{
Nonparametric Econometric Methods and Applications
}

\author{
Thanasis Stengos \\ Department of Economics and Finance, University of Guelph, Guelph, ON N1G 2W1, Canada; \\ tstengos@uoguelph.ca
}

Received: 28 November 2019; Accepted: 28 November 2019; Published: 30 November 2019

\begin{abstract}
An area of very active research in econometrics over the last 30 years has been that of nonand semi-parametric methods. These methods have provided ways to complement more-traditional parametric approaches in terms of robust alternatives, as well as preliminary data analysis. The present Special Issue collects a number of new contributions, both theoretical and empirical that cover a wide spectrum of areas such as financial economics, microeconomics, macroeconomics, labor economics, and economic growth as well as statistical theory and methodology.
\end{abstract}

Keywords: nonparametric methods; semiparametric methods; local smoothing; wavelets

Non-parametric and semi-parametric methods have been used extensively in applied work over the last thirty years as they provide flexible alternatives to existing parametric techniques that traditionally have dominated econometric practice. These flexible methods provide robust ways to conduct data analysis that can lead empirical researchers to parametric models that can best approximate the unknown data generating processes under investigation. The field has expanded with important advances both in time series and cross-sectional frameworks and more recently in panel data settings, allowing for data-driven flexibility that has proved invaluable to applied researchers. The methodology has been enhanced by software developments that have made these methods easy to apply, something that has opened up a variety of potentially important and relevant applications in all areas of economics, microeconomics, macroeconomics and economic growth, finance, and labor. The present Special Issue collects a number of new contributions both at the theoretical level, as well as in terms of applications in the areas of nonparametric and semiparametric econometric methods. In particular, this collection of papers that cover areas such as developments in local smoothing techniques, splines, series estimators, and wavelets will add to the existing rich literature on these subjects and enhance our ability to use data to test economic hypotheses in a variety of fields, such as financial economics, microeconomics, macroeconomics, labor economics, and economic growth, to name a few.

The papers in the collection cover a number of different topics. Sun and Wu (2018) study the contemporaneous relationship between S\&P 500 index returns and log-increments of the market volatility index (VIX) via a nonparametric copula method, where they propose a conditional dependence index to investigate how the dependence between the two series varies across different segments of the market return distribution. Kalaitzidakis et al. (2018) use a smooth coefficient semi-parametric model to examine the effect of emissions, as measured by carbon dioxide $\left(\mathrm{CO}_{2}\right)$, on economic growth among a set of OECD countries during the period 1981-1998 and they estimate directly the output elasticity of emissions. Yan and Li (2018) developed a nonparametric method to estimate a conditional quantile function for a panel data model with additive individual fixed effects; a model that can be applied to a variety of circumstances. Tzeremes (2018) examines the effect of financial development on countries' production efficiency levels and develops robust (order-m) time-dependent conditional nonparametric frontier estimators in order to measure 87 countries' production efficiency 
levels over the period 1970-2014. Eroğlu and Soybilgen (2018) apply wavelet methods in the popular augmented Dickey-Fuller and M types of unit root tests, and they perform an extensive comparison of the wavelet-based unit root tests which also includes recent contributions in the literature. Chen and Sun (2018) compare the finite sample performance of three non-parametric threshold estimators via the Monte Carlo method and they find that the finite sample performance of the three estimators is not robust to the position of the threshold level along the distribution of the threshold variable, especially when a structural change occurs at the tail part of the distribution. Jensen and Maheu (2018) examine the presence of volatility feedback in the often debated risk-return relationship by modeling the contemporaneous relationship between market excess returns and log-realized variances with a nonparametric, infinitely-ordered, mixture representation of the observables' joint distribution. Luong and Dokuchaev (2018) address the forecasting of realized volatility for a financial time series using the heterogeneous autoregressive model (HAR) and machine learning techniques, and they find that their proposed model offers improvements when applied to historical high-frequency data. Koroglu (2019) investigates the public debt and economic growth relationship using the semi-parametric smooth coefficient approach that allows democracy to influence this relationship and parameter heterogeneity in the unknown functional form and addresses the endogeneity of variables. Reza and Rilstone (2019) extend Horowitz's smoothed maximum score estimator to discrete-time duration models. They derive both asymptotic properties and examine finite sample performance through Monte Carlo simulations. Finally, Melecký et al. (2019) apply data envelopment analysis (DEA) methodology to compare the dynamic efficiency of European countries over the last decade.

All of the above papers cover many diverse applications and contributions of nonparametric methods that we hope will add to the already rich literature to become useful additions to both applied and theoretical econometricians alike.

Funding: This research received no external funding.

Acknowledgments: The editor wants to acknowledge the expert advice of the anonymous reviewers who greatly improved the substance and presentation of the included papers with their insightful comments.

Conflicts of Interest: The authors declare no conflict of interest.

\section{References}

Chen, Chaoyi, and Yiguo Sun. 2018. Monte Carlo Comparison for Nonparametric Threshold Estimators. Journal of Risk and Financial Management 11: 49. [CrossRef]

Eroğlu, Burak, and Barış Soybilgen. 2018. On the Performance of Wavelet Based Unit Root Tests. Journal of Risk and Financial Management 11: 47. [CrossRef]

Jensen, Mark J., and John M. Maheu. 2018. Risk, Return and Volatility Feedback: A Bayesian Nonparametric Analysis. Journal of Risk and Financial Management 11: 52. [CrossRef]

Kalaitzidakis, Pantelis, Theofanis P. Mamuneas, and Thanasis Stengos. 2018. Greenhouse Emissions and Productivity Growth. Journal of Risk and Financial Management 11: 38. [CrossRef]

Koroglu, Mustafa. 2019. Growth and Debt: An Endogenous Smooth Coefficient Approach. Journal of Risk and Financial Management 12: 23. [CrossRef]

Luong, Chuong, and Nikolai Dokuchaev. 2018. Forecasting of Realised Volatility with the Random Forests Algorithm. Journal of Risk and Financial Management 11: 61. [CrossRef]

Melecký, Lukáš, Michaela Staníčková, and Jana Hančlová. 2019. Nonparametric Approach to Evaluation of Economic and Social Development in the EU28 Member States by DEA Efficiency. Journal of Risk and Financial Management 12: 72. [CrossRef]

Reza, Sadat, and Paul Rilstone. 2019. Smoothed Maximum Score Estimation of Discrete Duration Models. Journal of Risk and Financial Management 12: 64. [CrossRef]

Sun, Yiguo, and Ximing Wu. 2018. Leverage and Volatility Feedback Effects and Conditional Dependence Index: A Nonparametric Study. Journal of Risk and Financial Management 11: 29. [CrossRef] 
Tzeremes, Nickolaos G. 2018. Financial Development and Countries' Production Efficiency: A Nonparametric Analysis. Journal of Risk and Financial Management 11: 46. [CrossRef]

Yan, Karen X., and Qi Li. 2018. Nonparametric Estimation of a Conditional Quantile Function in a Fixed Effects Panel Data Model. Journal of Risk and Financial Management 11: 44. [CrossRef]

(C) 2019 by the author. Licensee MDPI, Basel, Switzerland. This article is an open access article distributed under the terms and conditions of the Creative Commons Attribution (CC BY) license (http://creativecommons.org/licenses/by/4.0/). 